Acta Crystallographica Section E

Structure Reports

Online

ISSN 1600-5368

Amir H. Mahmoudkhani ${ }^{a *}$ and Vratislav Langer ${ }^{b}$

a Department of Chemistry, Göteborg University, SE-41296 Göteborg, Sweden, and 'bepartment of Inorganic Environmental Chemistry, Chalmers University of Technology, SE-41296 Göteborg, Sweden

Correspondence e-mail: amir@inoc.chalmers.se

\section{Hexamethylenediammonium hydrogenphosphite. Erratum}

In the paper by Mahmoudkhani \& Langer [Acta Cryst. (2001), E57, o866-o868], the title was published incorrectly. The correct title is 'Pillared layered hydrogen-bonded network in hexamethylenediammonium hydrogenphosphite'. Also, Fig. 2 was shown in a truncated form. A revised PDF version of the article is available. 